\title{
The role of G-protein-coupled receptor 120 in fatty acids sensing in chicken oral tissues
}

\author{
Ryo Sawamura ${ }^{\mathrm{a}, 1}$, Yuko Kawabata ${ }^{\mathrm{b}, 1}$, Fuminori Kawabata ${ }^{\mathrm{c}, *}$, \\ Shotaro Nishimura ${ }^{\mathrm{b}}$, and Shoji Tabata ${ }^{\mathrm{b}}$
}

${ }^{a}$ Laboratory of Functional Anatomy, Department of Bioresource Sciences, Graduate School of Bioresource and Bioenvironmental Sciences, Kyushu University, Fukuoka, Japan

${ }^{\mathrm{b}}$ Faculty of Agriculture, Kyushu University, Fukuoka, Japan

'Institute for Advanced Study, Kyushu University, Fukuoka, Japan

* Corresponding author: Fuminori Kawabata, Institute for Advanced Study, Kyushu University, 6-10-1 Hakozaki, Higashi-ku, Fukuoka 812-8581, Japan. Tel.: +81-92-642-2944. Fax: $+81-92-642-2944$

E-mail address: kawabata@agr.kyushu-u.ac.jp

${ }^{1}$ These authors contributed equally to this work. 


\section{ABSTRACT}

Clarification of the mechanism of chickens' taste sense will provide meaningful information for creating and improving new feedstuff for chickens, because the character of taste receptors in oral tissues affects feeding behavior in animals. Although fatty acids are partly recognized via G-protein coupled receptor 120 (GPR120) for fat taste in mammalian oral tissues, the fat taste receptor of chickens has not been elucidated. Here we cloned chicken GPR120 (cGPR120) from the chicken palate, which contains taste buds. By using $\mathrm{Ca}^{2+}$ imaging methods, we identified oleic acid and linoleic acid as cGPR120 agonists. Interestingly, in a behavioral study the chickens preferred corn oil-rich feed over mineral oil (control oil)-rich feed. Because corn oil contains high amounts of oleic acid and linoleic acid, this result was thought to be reasonable. Taken together, the present results suggest that cGPR120 is one of the functional fat taste receptors in chickens.

Key words: fatty acid, GPR120, fat taste receptor, chicken 


\section{Introduction}

In chickens, the taste sense is one of the most important senses for acquiring and choosing

feeds, as are the smell and visual senses [1]. The recognition of chicken taste sense offers

opportunities to create and improve the feedstuffs of chickens, and to contribute to the

understanding of mammalian taste senses in comparisons with the functioning of mammalian

taste receptors. In mammals, there are five basic tastes: sweet, bitter, umami, sour, and salty.

However, in chickens, although there are four taste receptor genes (for bitter, umami, sour, and

salty), the T1R2 gene, which is for the sweet taste receptor, is absent [1].

We revealed that almost all of the taste buds of chicken exist in the palate and the floor of

oral cavity rather than on the tongue [2], and we found that gustducin, which is a specific $\mathrm{G}$

protein in a subset of taste cells, is expressed in taste buds in chickens [3]. In another study our

findings elucidated that the chicken strain which has a lower number of taste buds compared to

other strains has lower sensitivity for bitter taste than the other strains [4]. We also observed that

the primary culture cells of isolated taste buds from the chicken palate show sensitivity to bitter

and umami tastants, and these tastants increased the intracellular calcium concentration of these

primary culture cells [5].

It was reported that bitter taste receptors, i.e., T2Rs, and umami taste receptor, T1R1/T1R3, 
were cloned in chicken, and some agonists of these receptors were identified [6,7]. Although it is thought that these taste receptors expressed in chicken taste buds sense tastants, it is assumed that there are a number of unknown taste receptors in chickens. In the present study, we focused on fat-taste receptors in chickens. Although fat taste is not among the five basic tastes, it is an important taste to detect fatty acids, which are necessary nutrients for animals.

G-protein-coupled receptor 120 (GPR120) is one of the fatty acid receptors [8], and it is expressed in oral taste cells of mammals $[9,10,11]$. In mice, taste preference for linoleic acid and oleic acid is partly mediated by GPR120 [12]. In chickens, although it has been reported that gustation has important roles in the determination of oil preference [13], the detection mechanisms of fat taste have not been elucidated. The purpose of the present study was to clone the chicken fat-taste receptor GPR120 and analyze its functions.

\section{Materials and methods}

\subsection{Chemicals}

Oleic acid and linoleic acid were purchased from Sigma-Aldrich (St. Louis, MO, USA), dissolved in dimethyl sulfoxide (DMSO) and stored at $-20^{\circ} \mathrm{C}$. The DMSO stock was diluted with a standard bath solution containing $140 \mathrm{mM} \mathrm{NaCl}, 5 \mathrm{mM} \mathrm{KCl}, 2 \mathrm{mM} \mathrm{MgCl}, 2 \mathrm{mM} \mathrm{CaCl}_{2}$, 
$10 \mathrm{mM}$ HEPES and $10 \mathrm{mM}$ glucose at $\mathrm{pH} 7.4$, adjusted with $\mathrm{NaOH}$ just before each experiment.

\subsection{Animals}

Rhode Island Red strain 0-wk-old chicks were used for this research. The study was carried out according to the Guide for Animal Experiments issued by Kyushu University, the Law Concerning the Human Care and Control of Animals (Law No. 105; October 1, 1973), and the Japanese Government Notification on the Feeding and Safekeeping of Animals (Notification No. 6; March 27, 1980).

\subsection{Chicken GPR120 construct}

Total RNA was isolated from the palate of chicks, and first-strand cDNA was synthesized by reverse transcription. Then, deduced open reading frames (ORFs) of chicken GPR120 (cGPR120) were amplified and sequenced. The polymerase chain reaction (PCR) primers were designed based on the genome assemblies of the cGPR120 (XM_003641481.2). The primers were designed as exon-spanning. The PCR products of the ORFs were subcloned into the pcDNA3.1(+) expression vector by using the In-Fusion HD Cloning Kit (Takara Bio, Otsu, 
Japan). The entire sequence of $c G P R 120$ was confirmed.

\subsection{Cell culture}

Human embryonic kidney (HEK)-derived 293T (HEK293T) cells were maintained in Dulbecco's modified Eagle's medium (DMEM high glucose, Wako Pure Chemical Industries, Osaka, Japan) containing 10\% fetal bovine serum (FBS, GE Healthcare, Buckinghamshire, UK), and Penicillin-Streptomycin Solution $(\times 100)\left(\right.$ Wako) at $37^{\circ} \mathrm{C}$ in $5 \% \mathrm{CO}_{2}$.

\section{5. $\mathrm{Ca}^{2+}$ imaging by confocal microscopy}

For the $\mathrm{Ca}^{2+}$ imaging experiments, HEK293T cells were transfected with either empty vector pcDNA3.1(+) or cGPR120/pcDNA3.1 (+) by using ScreenFect ${ }^{\mathrm{TM} A}$ (Wako) on coverslips coated by poly-D-lysine $(0.1 \mathrm{mg} / \mathrm{mL})$. After transfection, the cells were incubated for $48 \mathrm{~h}$ at $37^{\circ} \mathrm{C}$ and $5 \% \mathrm{CO}_{2}$. Then, the cells were loaded with $1.25 \mu \mathrm{M}$ Fluo 4-AM solution for $1 \mathrm{~h}$ at $37^{\circ} \mathrm{C}$ and $5 \% \mathrm{CO}_{2}$ in the dark. Fluo $4-\mathrm{AM}$ solution was prepared according to the manufacturer's manual (Dojindo Laboratories, Kumamoto, Japan).

The cover slips were washed with the standard bath solution, and Fluo-4 fluorescence was measured in the standard bath solution by using a confocal laser scanning microscope (Nikon 
A1R, Nikon Co., Tokyo). The coverslips were mounted in a chamber connected to a gravity flow system to deliver various stimuli. Chemical stimulation was applied by running a bath solution containing various chemical reagents. Cell viability was confirmed by responses to 5 $\mu \mathrm{M}$ ionomycin (Dojindo).

\subsection{Dose response assay of $\mathrm{Ca}^{2+}$ imaging}

For the dose-response assay of the intracellular $\mathrm{Ca}^{2+}$ concentration, we seeded cells in a 96-well clear bottom plate (Corning, Lenexa, KS) coated with poly-D-lysine $(0.1 \mathrm{mg} / \mathrm{mL})$ after transfection. Forty-eight hours after transfection, we loaded $100 \mu \mathrm{L}$ of $5 \mu \mathrm{M}$ Fura 2-AM solution per well. Fura 2-AM solution was prepared according to the manufacturer's manual for the Calcium Kit II-Fura 2 (Dojindo). After incubation for $1 \mathrm{~h}$ in the dark at $37^{\circ} \mathrm{C}$, calcium imaging was done using an Infinite ${ }^{\circledR} 200$ PRO microplate reader (Tecan Group, Männedorf, Switzerland). The assay was done at about $20^{\circ} \mathrm{C}$, and $30 \mu \mathrm{L}$ of $100-3000 \mu \mathrm{M}$ oleic acid or linoleic acid solution diluted by the standard bath solution was applied. Cell activity was analyzed by the differences between $\mathrm{R}_{\max }$ (the max value of the ratio of fluorescence intensity at $340 \mathrm{~nm}$ and $380 \mathrm{~nm}$ ) after stimulus and $\mathrm{R}_{0}$ (average value of the ratio) before stimulus. 


\subsection{The two-feed choice test}

Rhode Island Red strain chicks were raised in a box brooder (Showa Furanki, Saitama, Japan) under a 14:10 h light/dark cycle (5:00-19:00 light). Tap water was used for the chicks' drinking water. The experiment was done at room temperature in the box brooder that was familiar for the chicks. Chicks entered into the individual space divided by woven metal wire, reducing the stress created by seeing other chicks. Commercial feedstuff was used for this experiment (Powerlayer17Y, JA Kitakyushu Kumiai Shiryo, Fukuoka, Japan). To create the corn oil-rich diet, we mixed $15 \mathrm{~g}$ of corn oil (Ajinomoto Co., Tokyo) with $40 \mathrm{~g}$ of the commercial feedstuff. For the control diet, we mixed $15 \mathrm{~g}$ of mineral oil (Kaneda Co., Tokyo) with $40 \mathrm{~g}$ of the commercial feedstuff. Mineral oil (liquid paraffin) was used as the control oil because it is a bland and innocuous oil, as described [14]. Oleic acid and linoleic acid are rich in corn oil, and these percentages in total fatty acid of corn oil are $29.8 \%$ and $54.9 \%$, respectively [15]. The prepared portions of the two diets were placed simultaneously in the chick's individual space, side by side, and left there for $7 \mathrm{~h}$; we measured the feed intake at the end of the 7-h period. Water was given freely. To avoid the effect of place, the positioning of the two experimental diets was switched at $3.5 \mathrm{~h}$. On the day prior to the experimental day, we gave an intermediate feedstuff (mixed with $15 \mathrm{~g} 50 \%$ corn oil/50\% mineral oil with $40 \mathrm{~g}$ of the commercial feedstuff) 
to the chicks to help them become accustomed to the two experimental diets.

\subsection{Statistical analysis}

The data are expressed as the mean \pm SEM. Statistical analyses were done by paired $t$-test, unpaired $t$-test, or Tukey-Kramer test. The analyses were conducted using the IGOR Pro software package (Version 6.34J, WaveMetrics, Portland, OR), and differences with $p$-values $<0.05$ were considered significant.

\section{Results}

\subsection{Cloning of chicken GPR120 from palate}

mRNA of $c G P R 120$ were detected in chicken palate by RT-PCR (data not shown). Then, we cloned $c G P R 120$ gene from chicken palate. After amplification in E. coli, we confirmed that the cDNA sequences of cloned $c G P R 120$ matched that in the predicted genomic sequences of the NCBI database (XM_003641481.2) except for three bases (Fig. 1). The translated product of the cloned $c G P R 120$ gene fully matched the database (XM_003641481.2).

3.2. Oleic acid and linoleic acid increased cytosolic $\mathrm{Ca}^{2+}$ concentrations through cGPR120 
After the stimulus of $100 \mu \mathrm{M}$ oleic acid, the cytosolic $\mathrm{Ca}^{2+}$ concentration was increased in cGPR120-expressing HEK293T cells (Fig. 2A,C). The mock cells were not affected by the same oleic acid stimulus (Fig. 2B). There was a significant difference in the cytosolic $\mathrm{Ca}^{2+}$ concentration between the cGPR120-expressing cells and the mock cells (Fig. 2D). These differences were also observed by $100 \mu \mathrm{M}$ linoleic acid (Fig. 2E).

\subsection{Desensitization of chicken GPR120 by repeated stimuli}

To analyze the desensitization properties of chicken GPR120, we applied the identified agonist to GPR120-expressing HEK293T cells two times. We found that the intracellular $\mathrm{Ca}^{2+}$ reactivity of the second application of linoleic acid was significantly diminished compared to that of the first application (Fig. 2F). There was a significant difference between the two applications (Fig. 2G).

\subsection{Dose responses of cGPR120 agonists}

We analyzed the dose-dependency of oleic acid and linoleic acid for cGPR120. Oleic acid significantly activated cGPR120 dose-dependently (Fig. 3A). Linoleic acid also significantly activated cGPR120 dose-dependently (Fig. 3B). 


\subsection{Feed choice test of different oil sources in chickens}

Because oleic acid and linoleic acid were identified as agonists of cGPR120, we then examined whether chickens have preference for corn oil that contains a lot of oleic acid and linoleic acid. In the feed choice test, the chicks' feed intake of the corn oil-rich diet was significantly larger than that of mineral oil-rich feed (Fig. 4).

\section{Discussion}

In this study, we cloned $c G P R 120$ gene from chicken palate and found that oleic acid and linoleic acid are agonists of cGPR120. These agonists activated cGPR120 dose-dependently. We also found in the behavioral study that the chicks tested prefer corn oil that contains oleic acid and is linoleic acid-rich, rather than mineral oil. These results suggest that cGPR120 is a key receptor for detecting fat taste in chickens. In this study, we observed that $c G P R 120 \mathrm{mRNA}$ was expressed in chicken palate by RT-PCR. Because there are a lot of taste buds in chicken palate [2], cGPR120 is predicted to be expressed in taste buds. Further studies are needed to reveal the expression patterns of cGPR120 in the palate by immunohistochemistry and in situ hybridization. 
Here, cGPR120 activity was desensitized by the repeated stimuli of linoleic acid.

Generally, because GPCRs are desensitized by repeated stimuli of agonists [16], the present results were reasonable in light of the functions of GPCRs. Further studies are needed to elucidate the desensitization mechanisms of cGPR120.

There was a discrepancy between the results of the confocal microscope assay (Fig. 2D) and those of the fluorometer assay (Fig. 3A) regarding the activity of cGPR120-expressing cells stimulated by the application of $100 \mu \mathrm{M}$ oleic acid. We thought that the transfection efficacy by lipofection was approx. $40 \%$, because we previously confirmed the transfection efficacy of the same conditions as those of the present study by using another vector, pTagRFP-actin vector (data not shown). In Figure 2D, we analyzed the cGPR120-expressing cells only because we can observe the individual cell activity by confocal microscope. However, we could not select cGPR120-expressing cells (in Fig. 3) because these assays were done using a fluorometer. Thus, the results shown in Figure 3 contained $60 \%$ non-transfected cells, and the sensitivity of the fluorometer assay was thought to be lower than that of confocal microscope assay in the present transfection conditions. Although these conditions caused the discrepancy, we showed that oleic acid and linoleic acid activate cGPR120 and that the activation is dose-dependent.

In summary, we cloned chicken GPR120 gene from the palate and observed that oleic 
acid and linoleic acid are agonists for cGPR120. We also showed that corn oil that contains high amounts of oleic acid and linoleic acid increase the feed preference in chickens. These findings may have potential to improve the yieldability of chicken products and to provide useful information for comparisons with mammalian fat taste receptors.

\section{Acknowledgments}

We thank Dr Koji Shibasaki (Gunma University) for providing HEK293T cells. This study was supported in part by a grant to F.K. from the Funds for the Development of Human Resources in Science and Technology, the Japan Science and Technology Agency. This work was also supported by a grant to F.K. from JSPS KAKENHI (\# 26850207). 


\section{References}

[1] E. Roura, M.W. Baldwin, K.C. Klasing, The avian taste system: Potential implications in poultry nutrition, Anim. Feed Sci. Technol. 180 (2013) 1-9.

[2] K. Kudo, S. Nishimura, S. Tabata, Distribution of taste buds in layer-type chickens: Scanning electron microscopic observations, Anim. Sci. J. 79 (2008) 680-685.

[3] K. Kudo, K. Wakamatsu, S. Nishimura, S. Tabata, Gustducin is expressed in the taste buds of the chicken, Anim. Sci. J. 81 (2010) 666-672.

[4] K. Kudo, J. Shiraishi, S. Nishimura, T. Bungo, S. Tabata, The number of taste buds is related to bitter taste sensitivity in layer and broiler chickens, Anim. Sci. J. 81 (2010) 240-244.

[5] K. Kudo, F. Kawabata, T. Nomura, A. Aridome, S. Nishimura, S. Tabata, Isolation of chicken taste buds for real-time $\mathrm{Ca}^{2+}$ imaging, Anim. Sci. J. 85 (2014) 904-909.

[6] M. Behrens, S.I. Korsching, W. Meyerhof, Tuning Properties of Avian and Frog Bitter Taste Receptors Dynamically Fit Gene Repertoire sizes, Mol. Biol. Evol. 31 (2014) 3216-3227.

[7] M.W. Baldwin, Y. Toda, T. Nakagita, M.J. O'Connell, K.C. Klasing, T. Misaka, S.V. Edwards, S.D. Liberles, Evolution of sweet taste perception in hummingbirds by transformation of the ancestral umami receptor, Science 345 (2014) 929-933.

[8] A. Hirasawa, K. Tsumaya, T. Awaji, S. Katsuma, T. Adachi, M. Yamada, Y. Sugimoto, S. Miyazaki, G. Tsujimoto, Free fatty acids regulate gut incretin glucagon-like peptide-1 secretion through GPR120, Nat. Med. 11 (2005) 90-94.

[9] S. Matsumura, A. Eguchi, T. Mizushige, N. Kitabayashi, S. Tsuzuki, K. Inoue, T. Fushiki, Colocalization of GPR120 with phospholipase-C beta 2 and alpha-gustducin in the taste bud cells in mice, Neurosci. Lett. 450 (2009) 186-190.

[10] S. Matsumura, T. Mizushige, T. Yoneda, T. Iwanaga, S. Tsuzuki, K. Inoue, T. Fushiki, GPR expression in the rat taste bud relating to fatty acid sensing, Biomed. Res. 28 (2007) 49-55.

[11] M.M. Galindo, N. Voigt, J. Stein, J. van Lengerich, J.D. Raguse, T. Hofmann, W. Meyerhof, M. Behrens, $G$ protein-coupled receptors in human fat taste perception, Chem. Senses 37 (2012) 123-139.

[12] C. Cartoni, K. Yasumatsu, T. Ohkuri, N. Shigemura, R. Yoshida, N. Godinot, J. le Coutre, Y. Ninomiya, S. Damak, Taste preference for fatty acids is mediated by GPR40 and GPR120, J. Neurosci. 30 (2010) 8376-8382.

[13] M. Furuse, R.T. Mabayo, J. Okumura, The role of gustation in oil preference in the chicken, Jpn. Poult. Sci. 33 (1996) 256-260. 
[14] T. Yoneda, K. Saitou, T. Mizushige, S. Matsumura, Y. Manabe, S. Tsuzuki, K. Inoue, T. Fushiki, The palatability of corn oil and linoleic acid to mice as measured by short-term two-bottle choice and licking tests, Physiol. Behav. 91 (2007) 304-309.

[15] Science and Technology Agency, Standard Tables of Food Composition in Japan, fatty acids section (in Japanese), 5th Revised and Enlarged ed., Printing Bureau of the Ministry of Finance, Tokyo, 2005.

[16] E. Kelly, C.P. Bailey, G Henderson, Agonist-selective mechanisms of GPCR desensitization, Br. J. Pharmacol. 153 Suppl 1 (2008) S379-388. 


\section{Figure legends}

Fig. 1. Nucleotide and protein sequences of chicken GPR120. The cDNA sequence of cloned cGPR120 matches that in the NCBI database (XM_003641481.2) except for three bases (black box). We identified one amino acid of unknown region (black box). Other protein sequences matches the database (XM_003641481.2).

Fig. 2. Oleic acid and linoleic acid increased the cytosolic $\mathrm{Ca}^{2+}$ concentration through chicken GPR120. (A) The representative data of the cytosolic $\mathrm{Ca}^{2+}$ increase by oleic acid (100 $\left.\mu \mathrm{M}\right)$ solution in HEK293T cells expressing cGPR120. (B) Oleic acid did not increase the cytosolic $\mathrm{Ca}^{2+}$ concentration in HEK293T cells transfected with empty vector (Mock). (C) Oleic acid increased the cytosolic $\mathrm{Ca}^{2+}$ concentration through cGPR120. Ionomycin was applied to confirm the cell viability. The data are means \pm SEM of 179 cells. Bars indicate the duration of chemical applications. (D) Oleic acid $(100 \mu \mathrm{M})$ and (E) linoleic acid $(100 \mu \mathrm{M})$ significantly increased the cytosolic $\mathrm{Ca}^{2+}$ concentration in cGPR120-expressing cells compared to mock cells. Data are the \% activity of the relative fluorescence units (RFU) peak value after oleic acid or linoleic acid stimulus to $5 \mu \mathrm{M}$ ionomycin. Data are the mean \pm SEM of seven coverslips' data. One coverslip had approx. 100-300 cells, and the averages of the 100-300 cells data were treated as one 
coverslip's data. ${ }^{* * *} p<0.0001$ by unpaired $t$-test. (F) The representative data of the cytosolic $\mathrm{Ca}^{2+}$ concentration changing in cGPR120-expressing HEK293T cells by repeated linoleic acid application. Ionomycin was applied to confirm cell viability. Data are the means \pm SEM of the RFU of 274 cells. Bars: the duration of chemical applications. (G) The cytosolic $\mathrm{Ca}^{2+}$ concentration was significantly reduced by repeated linoleic acid stimulus. The values of the first stimulus were set as $100 \%$. Data are the mean \pm SEM of six coverslips' data. One coverslip had approx. 200-300 cells, and the averages of the 200-300 cells' data were treated as one coverslip's data. ${ }^{* * *} p<0.0001$ by paired $t$-test.

Fig. 3. The dose-dependency of cGPR120 activation by oleic acid and linoleic acid. (A) Oleic acid significantly increased the cytosolic $\mathrm{Ca}^{2+}$ concentration dose-dependently in HEK293T cells expressing cGPR120. Mock cells were not activated by oleic acid. (B) Linoleic acid also significantly activated cGPR120-expressing cells dose-dependently. Although mock cells were slightly activated by $3 \mathrm{mM}$ linoleic acid, other doses did not activate mock cells. Data are the mean \pm SEM of four wells. Bars without a common letter differ significantly, $p<0.05$ by Tukey-Kramer test. 
Fig. 4. Feed intakes of feed-containing-mineral oil and feed-containing-corn oil during the two-feed choice test for 7 hours. Feed intake of feed-containing-corn oil was significantly bigger than that of feed-containing-mineral oil. Data are the mean $\pm \operatorname{SEM}(n=8) .{ }^{*} p<0.05$ by paired $t$-test. 


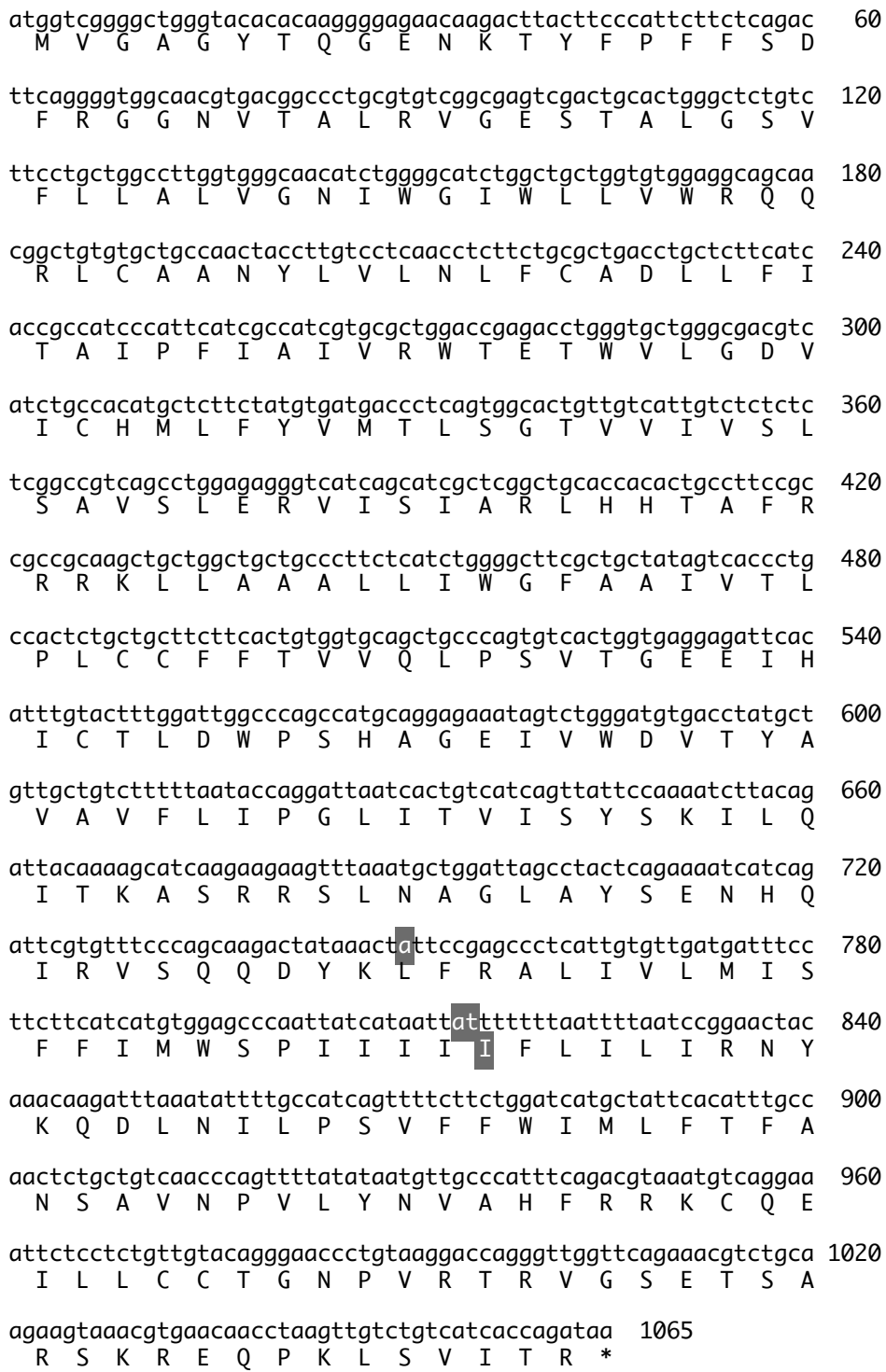

\section{Figure 1}

Sawamura et al. 
(A) cGPR120

Bath solution
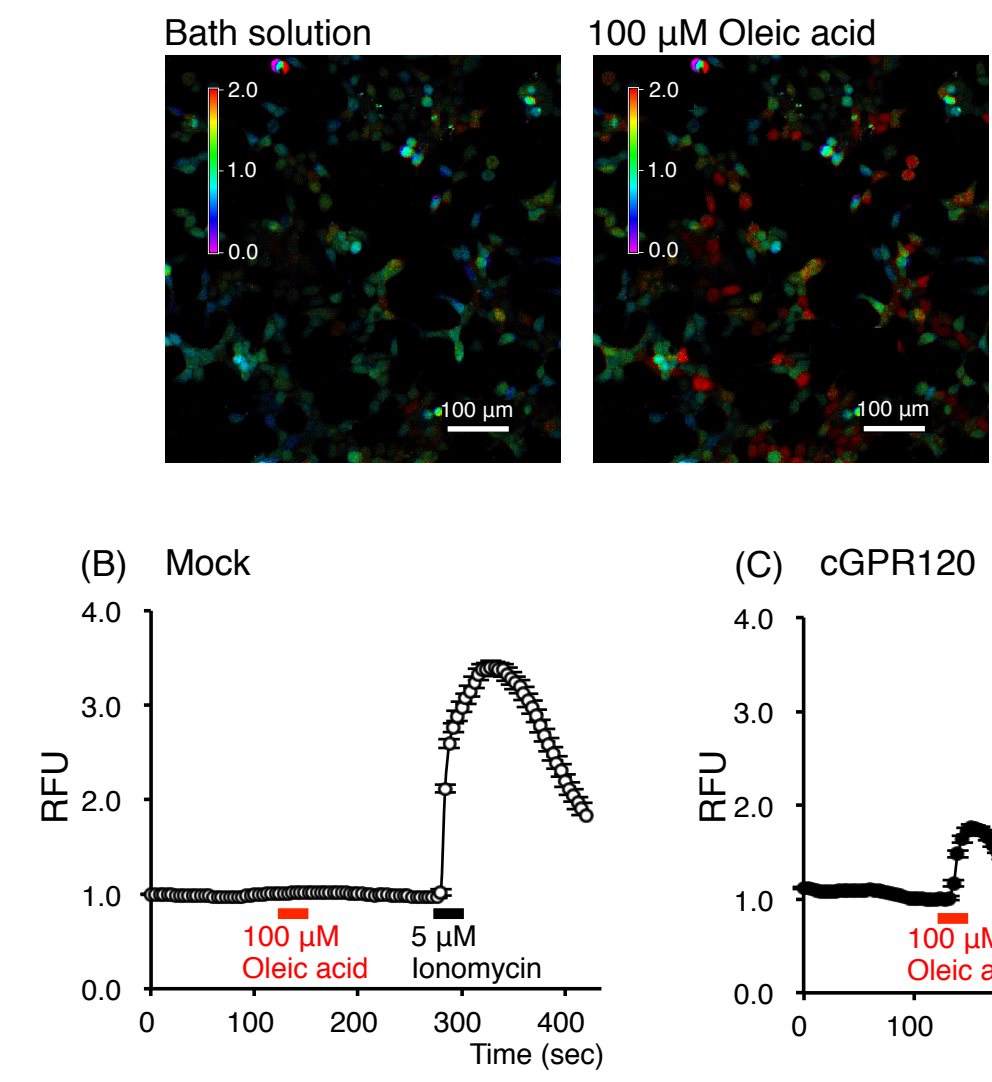

(C) cGPR120

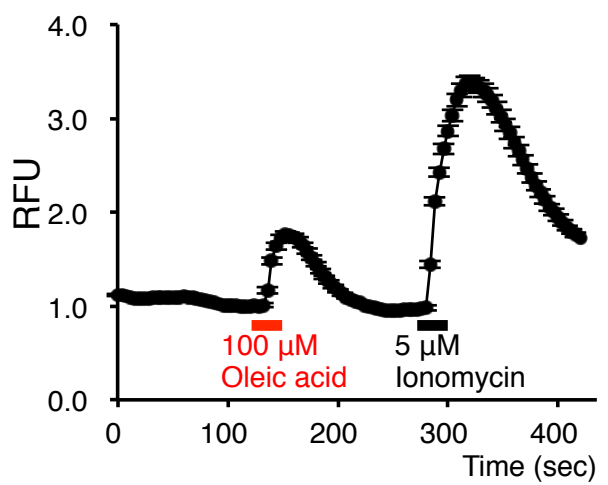

(D) $100 \mu \mathrm{M}$ Oleic acid

(E) $100 \mu \mathrm{M}$ Linoleic acid
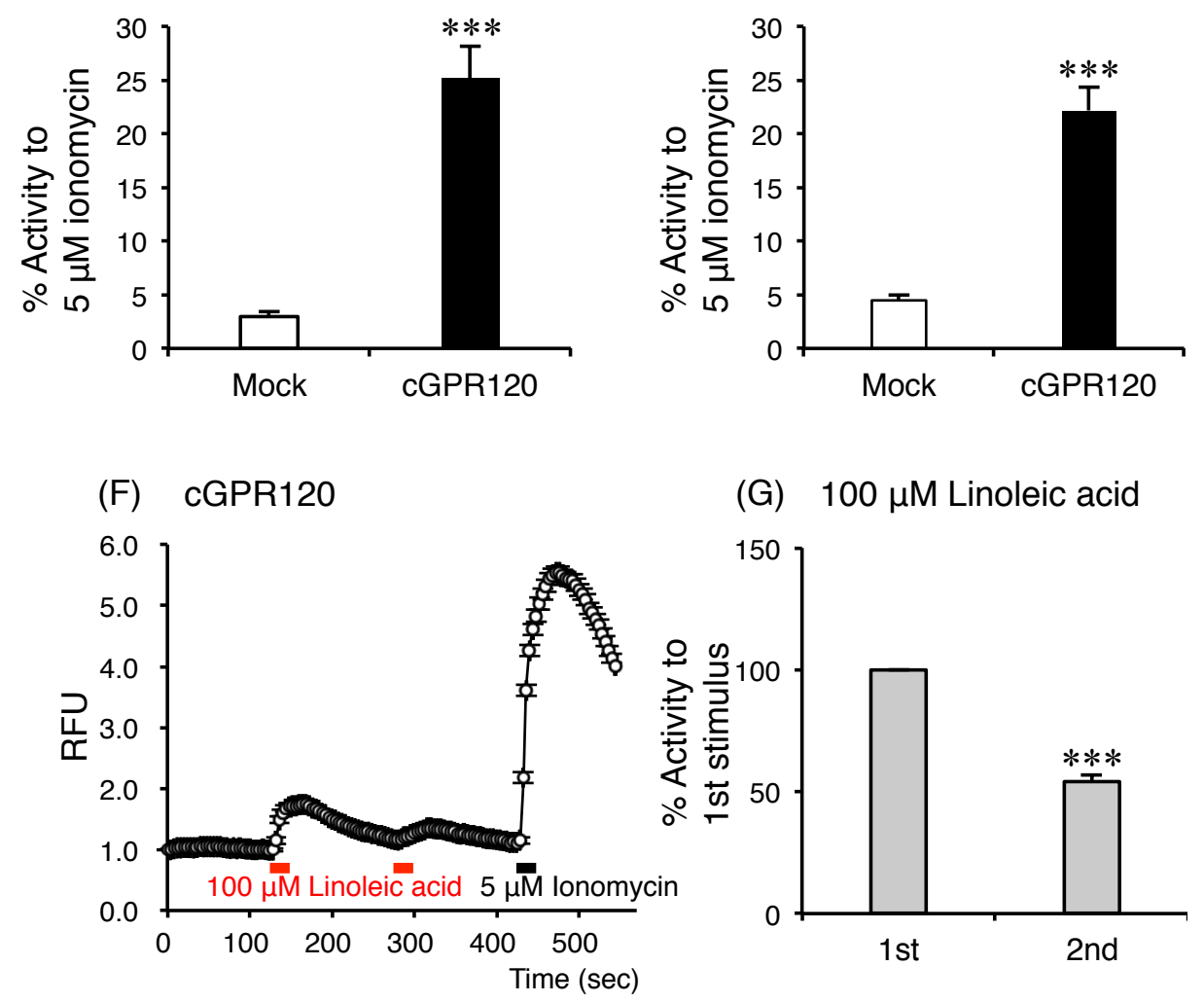

(G) $100 \mu \mathrm{M}$ Linoleic acid

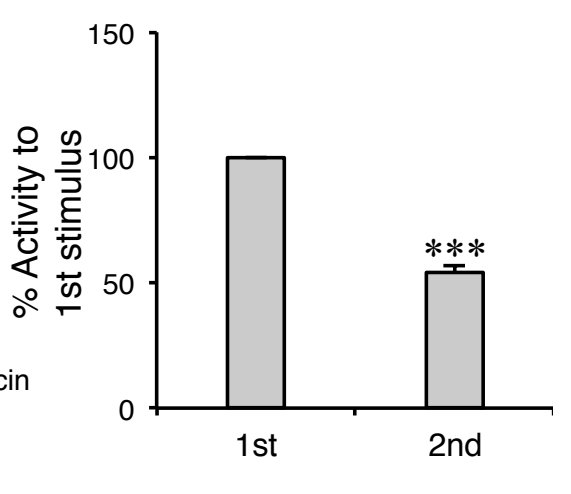

Figure 2

Sawamura et al. 

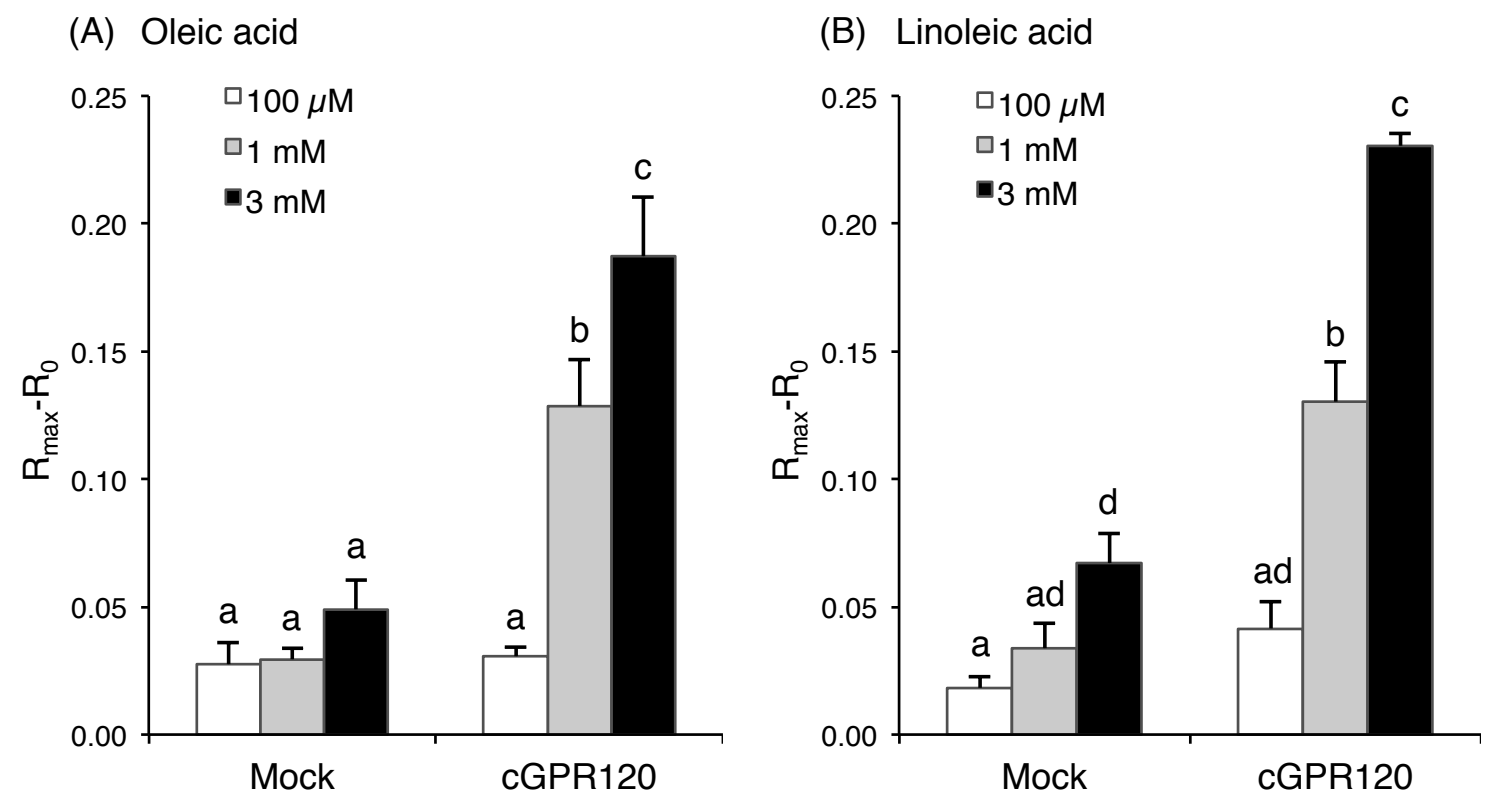

Figure 3

Sawamura et al. 


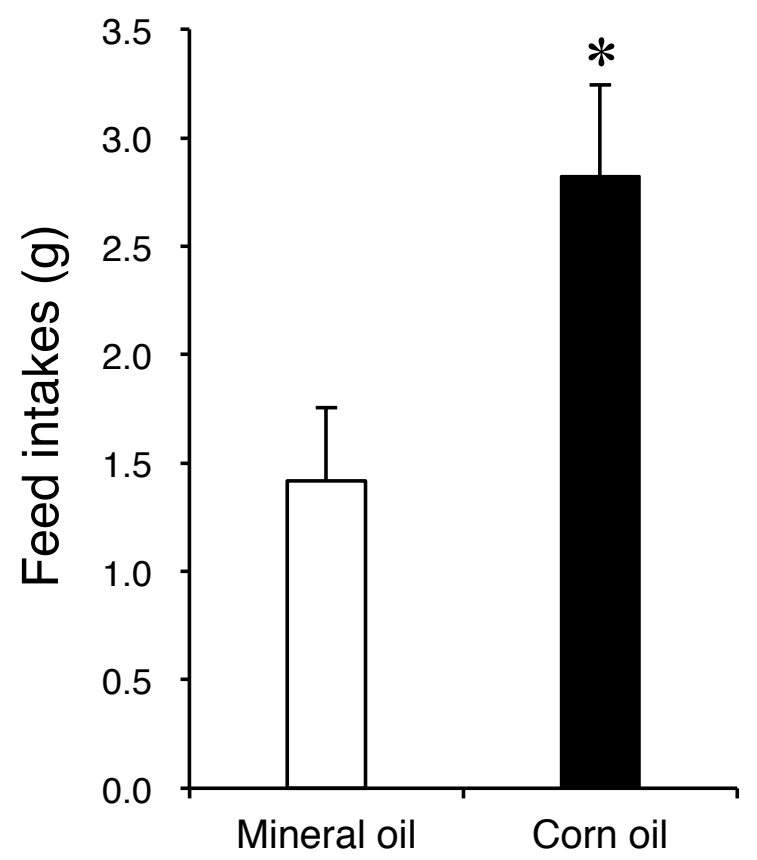

Figure 4

Sawamura et al. 